\title{
Assessment of landslide susceptibility for civil protection purposes by means of GIS and statistical analysis: lessons from the Province of Modena, Italy
}

\author{
Elena LIBERATOSCIOLI ${ }^{1 *}$, Cees J. VAN WESTEN ${ }^{2}$, Mauro SOLDATI ${ }^{1}$ \\ ${ }^{1}$ Università di Modena e Reggio Emilia, Dipartimento di Scienze Chimiche e Geologiche, Modena, Italy \\ ${ }^{2}$ University of Twente, Faculty of Geo-Information Science and Earth Observation (ITC), Enschede, The \\ Netherlands
}

Received 28 October 2017; Revised 14 November 2017; Accepted 2 December 2017

*Correspondence to: Elena Liberatoscioli, e-mail: elelib@gmail.com

\section{ABSTRACT}

This paper is focused on the analysis of landslide susceptibility for civil protection purposes. A methodology was developed and applied to support measures aiming at landslide risk mitigation. It is based on GIS and the Weight of Evidence (WofE) method, which was preferred among several other statistical approaches because it is suitable for large areas, easy to interpret and simple to program. The latter feature is important for implementing a GIS tool aimed to facilitate Civil Protection in the updating of susceptibility maps. An application of the methodology was performed in a mountainous and hilly area of the Northern Apennines (Italy) located in the Province of Modena where landslides are a critical issue in terms of civil protection due to the recurrent damages to buildings, roads and infrastructures. According to the Region Emilia-Romagna Landslide Inventory Map (RER LIM), shallow slides and earth flows are by far the most widespread mass movement types. Hence, the susceptibility assessment concerned these two types of movements. The choice of the training set, based on active landslides, took into account possible limitations of the input data. The predisposing factors were lithology, slope, curvature, Slope Position Index, aspect, land use, distance from roads. The validation was conducted through the PRC and SRC curves, and direct checking (comparison with past occurrences, multi-temporal orthophotos and field surveys). The resulting models predicted the location of landslides in an acceptable manner. One map for each type of landslides was produced and afterwards they were combined in a single document to improve their intelligibility in a civil protection framework.

KEYWORDS

Landslide; susceptibility assessment; civil protection; GIS; Northern Apennines; Italy 


\section{Introduction}

Prediction of landslide susceptibility and hazard for areas not currently subject to landsliding is fundamental for land planning and risk mitigation. At the same time, detecting the most susceptible areas to landslides is a challenging task since resources are becoming more and more scarce and exceptional rainfall events, which are likely to trigger landslides, are increasing (Borgatti and Soldati, 2010). Landslide susceptibility and hazard assessment is based on the assumption that hazardous phenomena that have occurred in the past can provide useful information for prediction of future occurrences (Soeters and van Westen, 1996). Many other authors agree on assuming that the same factors which triggered past landslides might cause future slope movements (Guzzetti et al., 1999; Soldati et al., 2009). Two basic methodologies are listed in relation to the analysis of the terrain conditions leading to slope instability (Soeters and van Westen, 1996): 1) direct mapping (experiencedriven applied-geomorphic approach), through which earth scientists evaluate direct relationships between landslides and their geological and geomorphological settings by direct observations; 2) indirect mapping which consists of mapping a large number of parameters considered to potentially influence landsliding and subsequently (heuristically, statistically, or through physicallybased modelling) analyzing their contribution with respect to the occurrence of slope instability phenomena, in order to identify the relationships between the two.

An important role is played by the scale of the analysis (International Association of Engineering Geology, 1976) and by the input data available (number, typology and quality), factor maps, but especially Landslide Inventory Map (LIM) quality (van Westen et al., 2005; Guzzetti et al., 2006; Galli et al., 2008; Guzzetti et al., 2012; Van Den Eeckhaut and Hervás, 2012; Chalkias et al., 2014; Petschko et al., 2014; Piacentini et al., 2015; Hussin et al., 2016). The methods of landslide susceptibility and hazard assessment are subdivided into heuristic, statistical and physically-based modelling approaches (Carrara et al., 1995; Soeters and van Westen, 1996; Guzzetti et al., 1999). In the heuristic approach the expert opinion of scientists conducting the survey is used to assess the hazard. This approach combines the mapping of mass movements and their geomorphological setting as the main input factor for hazard determination. In the statistical approach the combination of factors which have led to landslides in the past are determined statistically, and quantitative predictions are made for areas currently free of landslides but where similar conditions exist. Finally, the physically-based modelling approach is applicable only when the geomorphic and geological conditions are fairly homogeneous over the entire study area and the landslide types are simple. It is based on physical models (slope stability and hydrologic models), and it is generally applicable in the case of large-scale hazard zoning.

\subsection{Geographic and geomorphological settings}

The study area is located in the Province of Modena (Italy) and it is approximately $1,300 \mathrm{~km}^{2}$. It is intersected by the Northern Apennines and by the hills at the border of the mountain chain. The altitude ranges from $150 \mathrm{~m}$ to $2,165 \mathrm{~m}$ a.s.l. and the highest peak is Monte Cimone (Fig. 1).

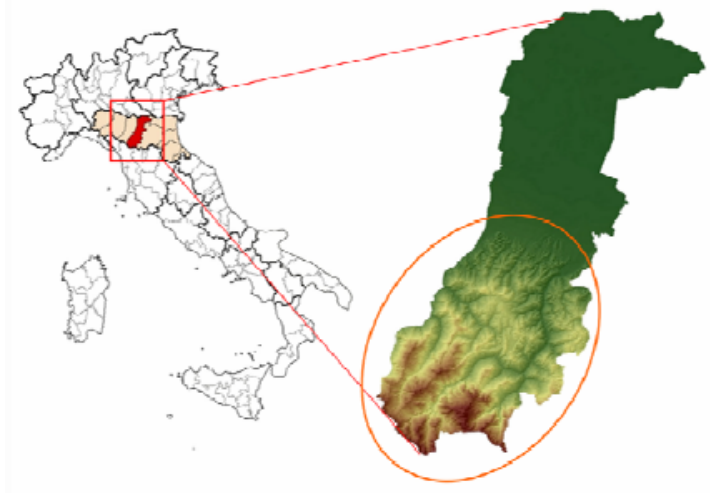

Figure 1 Location of the study area in Italy and in the Province of Modena

The main river basins are the Secchia, the Panaro and the Reno. Inside the study area there are 25 municipalities with a total population of 194,278 (Province of Modena, 2012). The physical features of the Modena Apennines landscape are the result of 
geomorphological processes which have been active mainly from the Upper Pleistocene on different lithological types under changing climatic and geodynamic conditions in terms of recurrence, spatial distribution and intensity (Castaldini et al., 2003; Siddiqui and Soldati, 2014).

In the study area there are erosional, structural, glacial and anthropogenic landforms. Badlands and landslides are widespread. Selective erosion, combined with geological structures, emphasize the contrast between calcarenitic or flysch rocks and ophiolitic outcrops with the gentle landscape dominated by the marly-clayey substratum. In the upper sector of the Modena Apennines, glacial landforms and moraines, dated to the Last Glacial Maximum, characterize the territory. Lastly, human activities, both quarrying and urbanization, have heavily re-shaped its natural morphological features.

\subsection{Landslide inventory}

Within the above framework, landslides are one of the most important geomorphic process that affects the area. According to the Region Emilia-Romagna Landslide Inventory Map (RER LIM), dated to 2006 with last updates in 2011, the total number of landslides in the area is 7,865 (Fig. 2). The total surface affected by landslide is $316 \mathrm{~km}^{2}$ corresponding to approximately $24.2 \%$ of the study area. In total $22 \%$ of the affected area is covered by active landslides, while the remaining $78 \%$ are considered as dormant.

Focusing on landslide types (both active and dormant), complex landslides occupy a large area $\left(201 \mathrm{~km}^{2}\right)$, followed by earth flows $\left(60.41 \mathrm{~km}^{2}\right)$; shallow landslides cover an area of $16.8 \mathrm{~km}^{2}$ and DGSDs covers $16.4 \mathrm{~km}^{2}$; "non-classified mass movements" extend for $19.46 \mathrm{~km}^{2}$; the remaining 2 $\mathrm{km}^{2}$ about are debris flows, rock falls and topples, as well as lateral spreads. The most frequent landslides are earth flows $(2,723)$ and shallow landslides $(2,812)$. The high number of large and periodically reactivated landslides depends primarily on geological causes, linked to the quality of rock masses and their state of physical weathering; the triggers are intense and/or prolonged precipitation events (Castaldini and Ghinoi, 2007). The reactivation of large dormant landslides still represents a threat in terms of hydrogeological risk (Bertolini et al., 2017).

\begin{tabular}{|l|c|c|}
\hline & $\begin{array}{c}\text { Nr. of } \\
\text { Lq km } \\
\text { (all LS) }\end{array}$ & $\begin{array}{c}\text { poligons } \\
\text { (only } \\
\text { active) }\end{array}$ \\
\hline Slides (S) & 16.8 & $\mathbf{1 8 5 4}$ \\
\hline $\begin{array}{l}\text { Complex landslides } \\
\text { (CL) }\end{array}$ & 201 & 360 \\
\hline Earth flows (EF) & 60 & $\mathbf{1 6 8 3}$ \\
\hline Debris flows (DF) & 0.64 & 18 \\
\hline $\begin{array}{l}\text { Not classified } \\
\text { landslides (NC) }\end{array}$ & 19.4 & 117 \\
\hline DGSDs & 16.4 & - \\
\hline Rock falls (RF) & 0.03 & 4 \\
\hline Lateral spreads (LSP) & 2.23 & - \\
\hline
\end{tabular}

TOT Nr. of Landslide: 7858

TOT Area of Landslide: $316.5 \mathrm{sq} \mathrm{km}$ Landslide index: $24.2 \%$

Active: $22 \%$ of total area of LS

Dormant: $78 \%$ of total area of LS

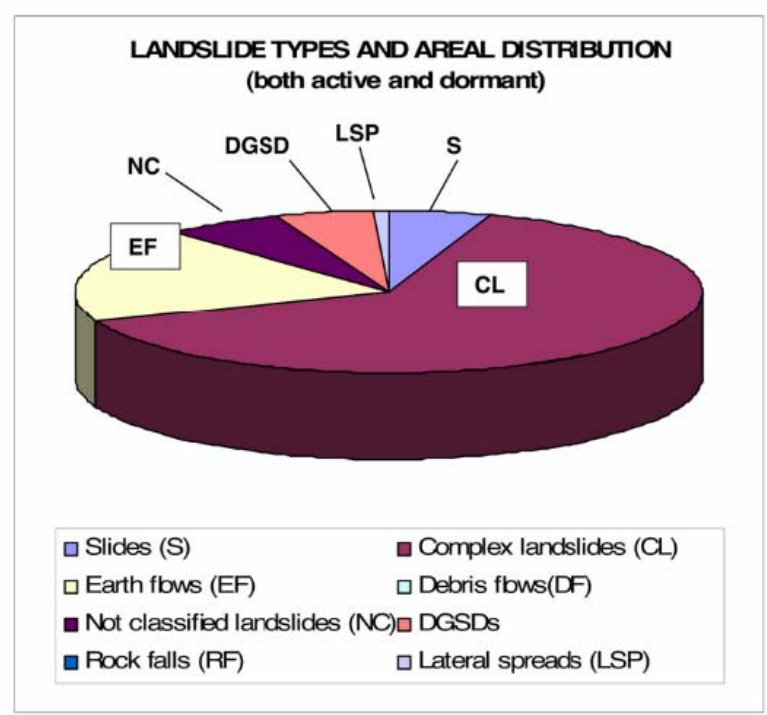

Figure 2 Landslide types and distribution in the study area (elaboration from RER LIM data). In terms of surface: $S=5.31 \% ; C L=63.51 \% ; E F=18.96 \% ; D F=0.2 \% ; N C=6.13 \% ; D G S D s=5.18 \% ; R F=0.01 \% ; L S P=0.7 \%$ 


\subsection{Main goals}

This research is an attempt to assess susceptibility for different type of landslides in the Province of Modena (Italy) for civil protection purposes. It was conducted in the framework of a wider project, briefly described in the next paragraph, whose main purpose was to re-organize the geographic information system and data related to risks which affect the provincial territory. The principal goals of the research were: 1 ) investigate if certain slopes, considered as stable at the moment, could be prone to landsliding in the future; 2) create a "priority scale" of landslide-prone areas where the local Civil Protection could concentrate efforts to prevent and mitigate damages; 3 ) identify a simple but effective methodology to assess susceptibility in order to update the map in the future and use it as a WebGIS layer and tool. A previous landslide susceptibility analysis was carried out by Generali and Pizziolo (2013) in the study area, based on a model at the scale of Region Emilia-Romagna with some differences in goals, methodologies and input from what is discussed in the present paper.

\subsection{The Risk Web-GIS}

Since October 2011, the Civil Protection work of the Province of Modena is supported by a new Web-GIS (Fig.3) with advanced geoservices that are compliant with INSPIRE (2007/2/CEE) and OCG (Open Geospatial Consortium) (Nicolini et al., 2012). Born as an evolution of the previous Data Collection System (named SRD), designed in 2001 by National Defence Department (DPCN) in Italy, and those of the Emilia-Romagna Region other than the Province of Modena, the new Web-GIS is intended to store and organize data necessary for assessing events and damage scenarios, during the phase of planning or when emergencies, linked to the hazardous phenomena which affect Province's territory (floods, landslides, earthquakes, industrial or other relevant incidents, forest fires), happen. The data stored in the geodatabase are mainly from the Province of Modena planning instruments (e.g. the main Province's plan, that is named PTCP 2009, emergency and other civil protection plans), but also from other public and private sources, and they concern the entire jurisdiction of Civil Protection that is the whole provincial territory from the plain to the high Apennine mountains.

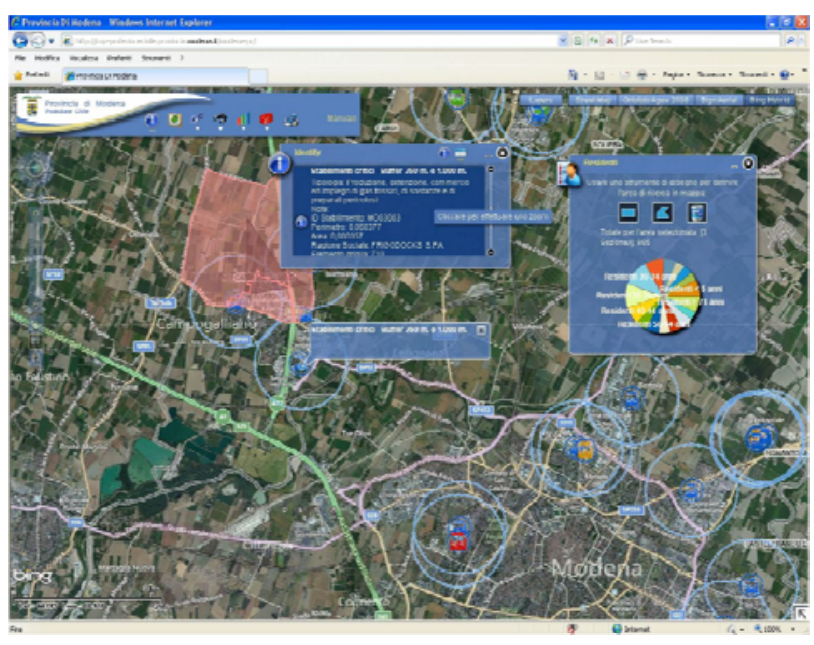

Figure 3 The Risk WebGIS of the Province of Modena Civil Protection and some of its advanced functionalities

The Risk WebGIS application, developed with ESRI standard FLEX programming language, is intended for the spreading of all the information managed by the new system (alphanumeric and geographic data; base and thematic layers; vectorial and raster data). Thanks to this web application, users can display and query thematic data, overlay them with base cartography (CTR - the regional technical map, ortophotos, satellite images etc.) and print their customized maps. Moreover, the WebGIS provides users with several decision support tools both for "simple" needs (e.g. how to get in the emergency area? where are the nearest civil protection structures and facilities?), and for performing advanced analysis: the Menu Census 2001 (Fig. 3) allow users to get spatial statistics without being specialists, such as information on resident population or on buildings' age of a customized area (defined by users drawing a polygon) involved or susceptible to be involved in an emergency. Other than the typical GIS tools for map browsing and querying (zoom, pan, identify etc.), the WebGIS offers different interesting functionalities, some of which are based on external 
geoservices (e.g. those of Google Maps, like Street View, or Bing). While the server engine (and the geodatabase) is physically installed only on a centralized machine in Marzaglia (Modena), where the Unified Centre for Civil Protection of Modena is located, the data entry client (based on ArcExplorer build 1750, a software solution for browsing GIS data distributed for free by ESRI) is also installed on users' computers and available especially for the COCs (the operations centres for civil protection at a municipality level).

The first large-scale emergency during which the new system was successfully tested is the 2012 Emilia Earthquake which caused 27 fatalities and damaged approximately 40,000 buildings. The application comprised the following activities: georeferencing and daily updating of the 49 emergency shelters; mapping a further 30 suitable areas for hosting people in case of worsening; and mapping the distribution of approximately 350 interventions (urgent temporary works) necessary to ensure public safety (e.g. shoring, demolition of unsafe buildings, barriers etc.).

\section{Landslide susceptibility assessment and mapping}

\subsection{Methods}

In the present study, a statistical approach, the Weight of Evidence method (Bonham-Carter, 1994) was selected to perform indirect landslide susceptibility assessment. It was selected among several statistical methods as it is suitable for determining landslide susceptibility in large areas with complex geological and geomorphological settings (Piacentini et al., 2012), it is easy to interpret, simple to program, and patterns with complex spatial geometry can be modelled with the same computational effort as those with simple geometry (Bohnam-Carter et al., 1989). Briefly, in this method positive and negative weights $\left(\mathrm{W}^{+}{ }_{i}\right.$ and $\mathrm{W}_{\mathrm{i}}^{-}$) are assigned to each class of the input factor maps, to indicate if and how much its presence/ absence is important for the occurrence of landslides. If the weight $\mathrm{W}^{+}{ }_{i}$ is positive, the presence of the factor (or of a specific classes of it) is favourable for the occurrence of landslides whilst, if it is negative, the presence of the factor is not favourable for the occurrence of landslides. $W_{i}^{-}$is used to estimate the importance of the absence of the factor in relation with landslide phenomena. Thus, when positive, it means that the absence of the factor is favourable for the occurrence of landslides. The total/final weight $\left(\mathrm{W}_{\text {map }}\right)$ of each factor, in a multi-class map where the presence of one factor implies the absence of the other factors of the same map, is defined by the following formula:

$$
W_{\text {map }}=W_{i}^{+}+W_{\text {mintotal }}+W_{i}
$$

where $\mathrm{W}_{\text {mintotal }}$ is the total weight in a multiclass map.

In order to quantify the spatial association between a map class and the occurrence of landslide, the contrast factor $C_{w}$ can be used (Bonham-Carter, 1994). It is the difference between $\mathrm{W}_{i}^{+}$and $\mathrm{W}_{i}^{-}$. The further the contrast factor is from zero, the more the factor is a significant predictor for the analysis. A positive contrast indicates a positive spatial correlation and vice versa for a negative contrast.

\subsection{Input data and sampling activity}

Most of the data used for the research illustrated in this paper are from the Cartography Archive of the Region Emilia-Romagna (RER) and RER Geological Service (SGSS) and are primarily as follows:

- Landslide Inventory Map (2006, with last updates in 2011);

- Geological Map;

- Land Use Maps (2008 and 1976);

- Street Map 1:5,000 from the Province of Modena;

- Digital Terrain Model 5x5 m.

The top three are all at the scale 1:10,000. Considering the selected statistical approach and the research purposes (civil protection), only the most frequent types of landslides were considered, earth flows and slides (Cruden and Varnes, 1996), in the susceptibility analysis. The two types were modelled separately because their driving factors and failure mechanisms are different. 


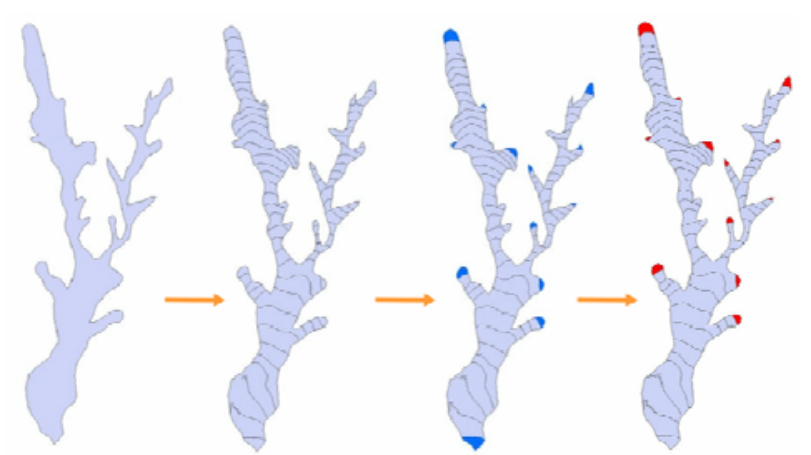

Figure 4 Schematic representation of the main steps utilized to extract the upper part of landslide polygons in ESRI ArcGIS 9.3.

As it is expected that susceptibility maps show the worst case scenario for mass movement initiation, one of the main problems encountered was that in the RER LIM scarps (depletion areas) are usually not mapped. However, the highest elevation points of the branches of each landslide polygon usually fall within the depletion area (Generali and Pizziolo, 2012). Therefore, the upper part of landslides polygons were used as training zones, assuming that they are most similar to scarps. They were extracted (Fig. 4) with a complex but semiautomatized procedure developed using ESRI ArcGIS 9.3.1 and three free extensions packages (Remove Small Polygons by Gonzalez, 2009; Find Adjacent Polygons by Buja, 2009; Topography Tools by Dilts, 2010 and Jenness Enterprise, 2006).

For both landslides types, the training sets were divided into two groups thanks to random selection as follows: the calibration set $(80 \%$ of the sampling polygons) to compute the model itself and the validation set ( $20 \%$ of the sampling polygons) to estimate its predictive power. Only active landslides were included in the training sets (van Westen et al., 2003; Poli and Sterlacchini, 2007). In the case of slides, rock slides were excluded from the analysis (the selection was based on the lithology map). The following analysis was conducted treating the two types of landslides separately as susceptibility assessment shows better results if one map for each types of movement, or movements comparable for materials and failure mechanisms, is computed (Zêzere, 2002; Fell et al., 2008).

\subsection{Factor maps}

The utilized factor maps were prepared with ArcGIS 9.3.1 and its extensions for raster analysis (mainly Spatial Analyst) converting vector maps (lithology, land use and distance from roads; Fig. 5-a) in to $5 \times 5$ $\mathrm{m}$ cells raster maps and deriving geomorphic parameters (slope, aspect, curvature and Slope Position Index) maps from DTM 5x5 m (Fig. 5-b). The lithology map was derived from RER Geological Map 1:10,000 (11 classes). The 1976 map was employed for land use as it is the first digitally available one, assuming that the map represents land use at the date of the landslide activation or reactivation (assumption supported by the analysis of the RER Historic Archive data). The selection of the 13 classes were operated taking in account two issues: 1) the significance of each land use in respect with landslide phenomena; 2) the compliance with the 2008 land use map classes which is considered to be representative of the current situation. Distances from roads were obtained by buffering a vector map of State, Provincial and local roads (4 intervals empirically determined; Fig. 5-a). The 9 aspect classes are $45^{\circ}$ each, while the 9 classes of the two slope steepness maps (different for the two types of considered landslides) were selected on the basis of a pre-analysis of maps with more than 70 classes, one degree spaced. The curvature map classes represent the 9 possible shapes that a hill slope unit can assume (Parsons, 1988) resulting from the combination of profile and forms (concave, convex and plain), represented in two maps derived from DTM in GIS environment and subsequently overlaid using ESRI Spatial Analyst Map Algebra operators. For the Slope Position Index map, the Slope Position Classification tool of ArcGIS extension Topography Tools (Jenness, 2006; Dilts, 2010) was used to compute the 6 classes. As it is a scale dependent factor, 4 different maps were produced using an equal number of circle radiuses for performing the Focal Statistic calculation (Neighborhood type) and the resulting maps were tested in susceptibility models taking into account the dimension of landslides (SIPI 10 and $20 \mathrm{~m}$ for slides, SIPI 50 and $100 \mathrm{~m}$ for earth flows). 
a) VECTOR FACTOR MAPS

\begin{tabular}{|c|c|}
\hline $\begin{array}{l}\text { LITHOLOGY } \\
\text { Derived from field } \\
\text { Sigla_litho of the } \\
\text { RER Geological } \\
\text { Map } 1: 10,000\end{array}$ & $\begin{array}{l}\text { 1) Dsc-Clay-shales } \\
\text { 2) Bp-Rocks with prevalent pelitic levels } \\
\text { 3) BI-Rocks with prevalent hard levels } \\
\text { 4) Blp-Rocks with hard and pelitic levels } \\
\text { 5) Dm-Maris } \\
\text { 6) As - Stratified rocks } \\
\text { 7) Dol - Clayey breccias } \\
\text { 8) Cs - Sands and slightly cemented sandstones } \\
\text { 9) Da-Clays, marly clays and silty clays } \\
\text { 10) A-Massive rocks } \\
\text { 11) Cc-Conglomerates and slightly cemented clasts } \\
\text { supported breccias }\end{array}$ \\
\hline $\begin{array}{l}\text { LAND USE } 1976 \\
\text { Supposed to be the } \\
\text { existing landuse at } \\
\text { the time of activation } \\
\text { or reactivation of the } \\
\text { most of LS; the } \\
\text { selected classes are } \\
\text { from level } 3 \text { and } 2 \text { to } \\
\text { be compliant with } \\
2008 \text { landuse }\end{array}$ & $\begin{array}{l}\text { 11) Urban zones } \\
\text { 12) Productive zones and infrastructures } \\
\text { 13) Quarries areas and similar } \\
\text { 14) Artificial green zones (non-agricultural areas) } \\
\text { 21) Non-permanent agricultural areas (arable areas) } \\
\text { 22) Permanent agricultural areas } \\
\text { 23) Stable meadows } \\
\text { 31) Forested areas } \\
\text { 33) Rade vegetated areas and rocks outcrops } \\
\text { 51) Continental water areas } \\
\text { 321) High altitude meadows } \\
\text { 322) Rade forested areas and areas with shrubs } \\
\text { 323) Young re-forested areas (artificial) }\end{array}$ \\
\hline $\begin{array}{l}\text { DISTANCE FROM } \\
\text { ROADS } \\
\text { Buffers on SS, SP, } \\
\text { SC: State, provincial } \\
\text { and local roads }\end{array}$ & $\begin{array}{l}\text { 20) } 0-20 \mathrm{~m} \\
\text { 50) } 20-50 \mathrm{~m} \\
\text { 100) } 50-100 \mathrm{~m} \\
>100 \mathrm{~m}\end{array}$ \\
\hline
\end{tabular}

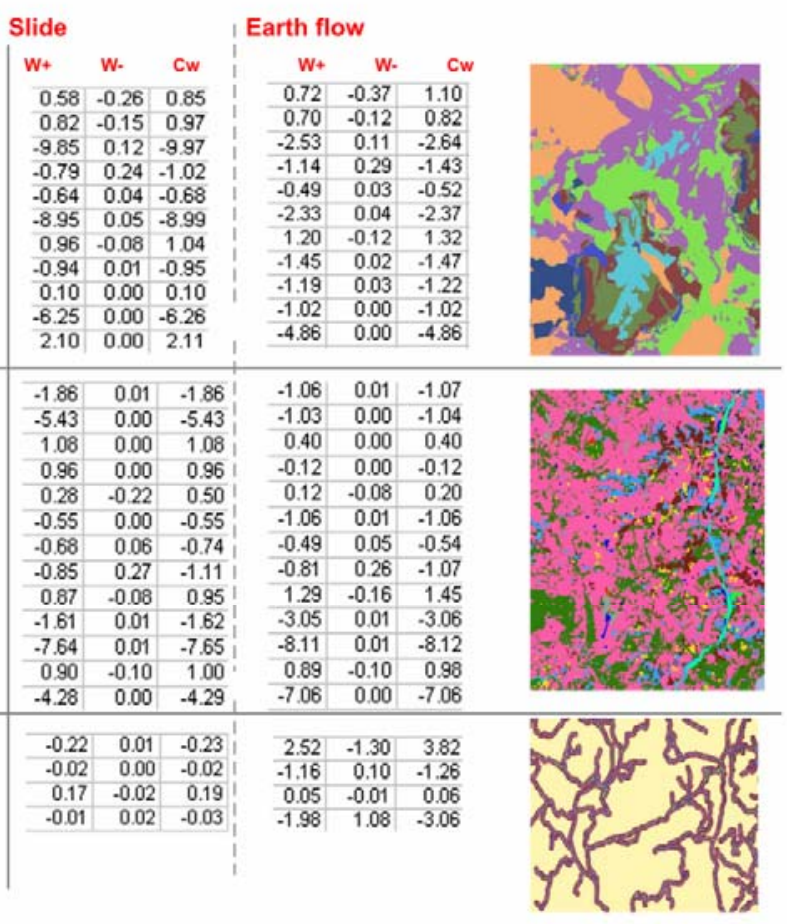

\section{b) DTM DERIVED FACTOR MAPS}

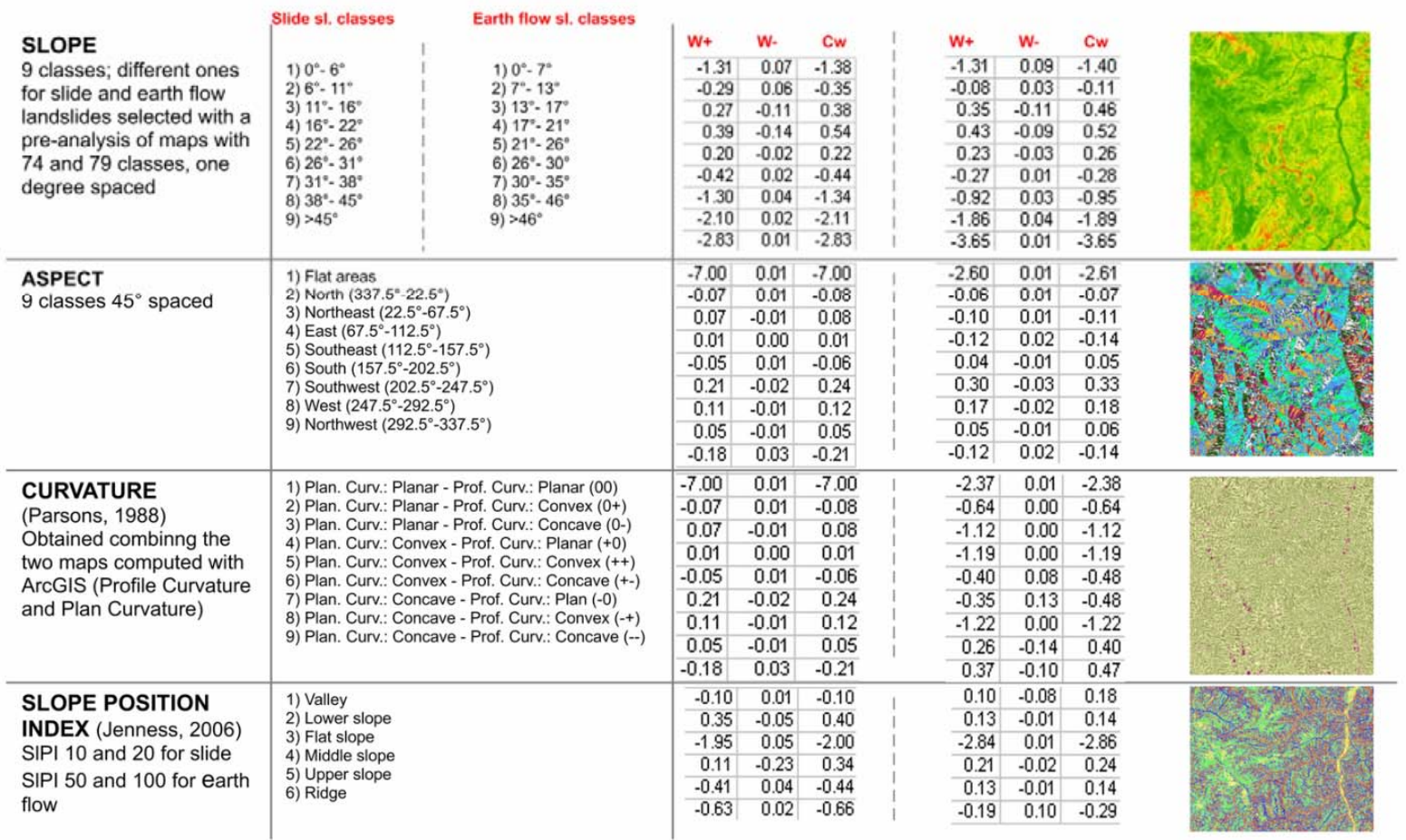

Figure 5 The whole set of factor maps introduced in landslide susceptibility assessment; a) shows vector factor maps; b) shows the DTM derived maps. The figure also reports the list of classes for each factor, the resultant weights and contrast factor $(\mathrm{W}+\mathrm{i}, \mathrm{W}-\mathrm{i}$ and $\mathrm{CW})$ for each types of landslides. In Figure $5-\mathrm{a}$, it was preserved the acronymous used in RER Geological Map for the description of lithology classes. 


\subsection{Validation}

Subsequently, the above factor maps were combined to obtain 18 scenarios ( 9 for each landslide types) and they were evaluated using Success Rate Curve (SRC) (Chung and Fabbri, 1999, 2003, 2008; van Westen et al. 2003; Sterlacchini et al., 2011) and Prediction Rate Curve (PRC) (Chung and Fabbri, 1999, 2003, 2008; Sterlacchini et al., 2011) methods. The first one, to evaluate the model fitting performance, is applied by plotting on the $x$ axis the cumulative percentage of susceptible areas (from highest value to the lowest one) and on the $y$ axis the cumulative percentage of landslides occurrences of the calibration set. The latter is a similar plot, but differs from the other as on the $y$ axis the cumulative percentage of landslides occurrences of the validation set is presented. It evaluates the predictive power of the model.The steeper is the curve (SRC or PRC), the best is the result as a greater number of landslides fall into the classes of the map with the highest susceptibility. In order to compare different curves it is possible to use the AUC (Area Under the Curve), which is the extent of the chart area under the curve expressed in percentage. In this paper only PRC curves are shown and commented, as they are considered particularly interesting for the aim of the paper. Hence, in figures 6 and 7, PRC curve respectively for slides and earth flows, are plotted.

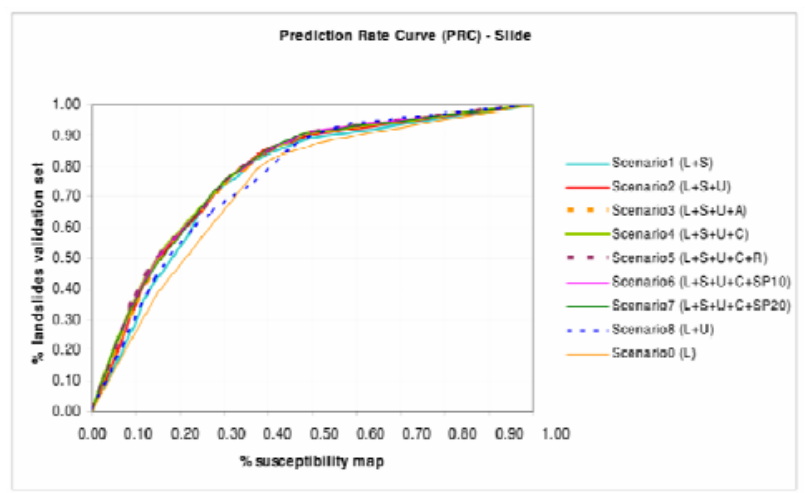

Figure 6 PRC Curve of the 9 scenarios computed for slides $(\mathrm{L}=$ lithology; $\mathrm{S}=$ slope; $\mathrm{U}=$ land use; $\mathrm{A}=$ aspect; $\mathrm{C}$ = curvature; $\mathrm{R}=$ distance from roads; $\mathrm{SP} 10=$ Slope Position Index (SIPI) 10 m; SP20 = SIPI 20 m)
They compare the 9 scenarios evaluated for each type of landslides. Analysing the plot in Fig. 6, PRC curve for slides, it can be noted that as the number of factors of the 9 scenarios increases, the curve becomes steeper.

At the same time, the AUC (Area Under the Curve) increases with the increasing of the number of factor maps from 0.74 (scenario 0) to 0.78 (scenarios from 2 to 7 ). From the curve in the Fig. 6, considering scenario 4 , it can be said that $30 \%$ of the map predicts $75 \%$ of slides in the study area, which is a good result. Analysing the plot in Fig. 7, PRC curve for earth flows, it can be noted that the 9 scenarios have high value of AUC except for scenarios 0 and 5 .

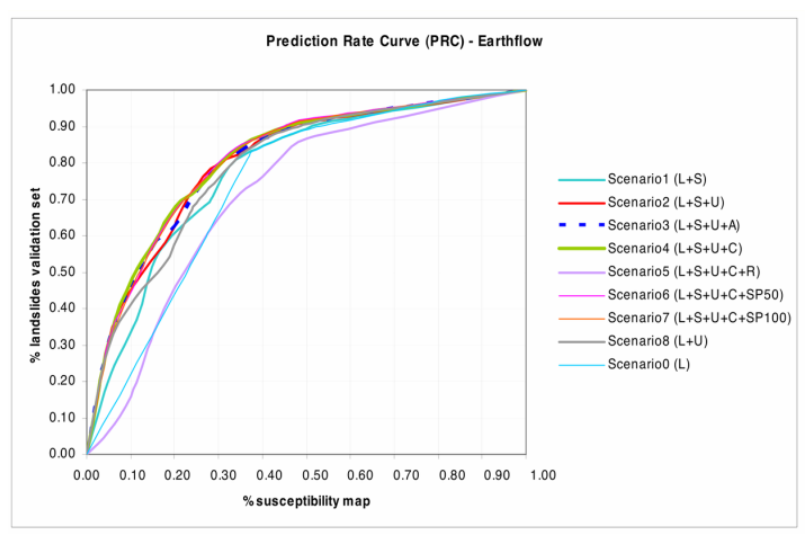

Figure $7 \mathrm{PRC}$ Curve of the 9 scenarios computed for earth flows $(\mathrm{L}=$ lithology; $\mathrm{S}=$ slope; $\mathrm{U}=$ land use; $\mathrm{A}=$ aspect; $\mathrm{C}$

$=$ curvature; $\mathrm{R}=$ distance from roads; $\mathrm{SP} 50=$ Slope Position Index (SIPI) 50 m; SP100 = SIPI 100 m)

This is to be expected for the first (one factor maps), but not for the latter (five factor maps). Scenario 5 differs from scenario 4 only for one factor (distance from roads), but the AUC of the first is only 0.72 , while the AUC of the latter is 0.81 . This means that introducing "distance from roads" the prediction rate worse significantly.

Considering scenario 4, it can be said that $30 \%$ of the map predicts $80 \%$ of earth flows in the study area, which is a very good result. 


\section{Application for civil protection purposes}

\subsection{Preparation of the map}

Aiming to ensure a greater usability for civil protection purposes, the two susceptibility maps were integrated into a unique document and compared with the existing landslides (Fig. 9). The conditional Map Algebra expression in ESRI Spatial Analyst, utilized to perform the integration, was the following:

Con(susc_map_ef $>$ susc_map_es,susc_map_ef, susc_map_es)

where susc_map_ef is the susceptibility map for earth flows and susc_map_es is the susceptibility map.

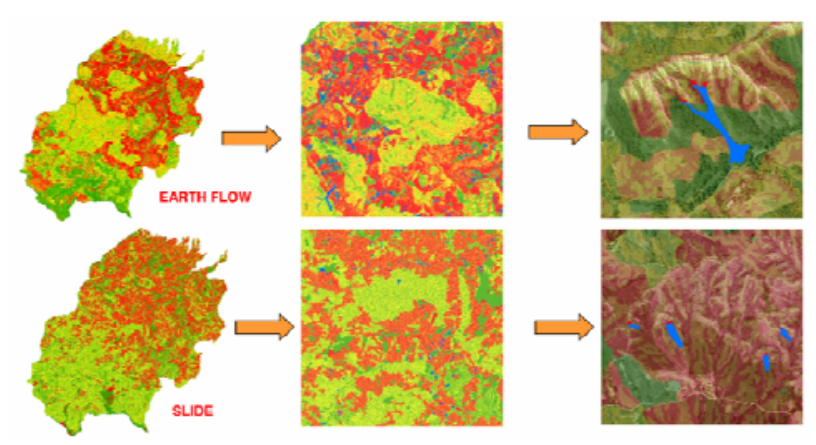

Figure 8 Susceptibility maps for the two types of landslide and a comparison with the existing landslides (red/blue polygons in the third image)

Briefly, it consists in assigning to each cell of the combined map the highest $\mathrm{W}_{\text {maptot }}$ value of the two orginal maps. In fact, it is often necessary to assess separately susceptibility for the different type of landslide affecting the area (i.e. for rock falls, small shallow landslides and deep-seated large landslides); these maps may be combined later onto one map (Fell et al., 2008).

The susceptibility maps for each landslide type, computed as illustrated in the above paragraph, could be useful for skilled users, such as geologists and geomorphologists, while the combined map of equation (3) could be easier to understand for nonspecialist users, such as in civil protection where users could be decision makers and disaster managers, rather than technicians. The intelligibility of the map depends also on the adopted symbols, number of classes and colours.

To define class intervals is a hard task since it could strongly influence the interpretation of the map and consequently drive civil protection decisions. Anyway, it was considered that if the map is left as the GIS software automatically displays, or the number of assigned classes is too high, nonspecialist users must interpret the map by themselves without having adequate knowledge on the real significance of the coloured pixels they are viewing. For this reason, two classification methodologies, among those which are available in ESRI ArcGIS, were experimented in order to define the map legend: Quantile and Natural Breaks (Jenks). A third, Equal interval methodology in which each class has an equal range of values, was dismissed a priori because it was considered unsuitable for representing the type of data discussed in this paper. In both cases, Quantile and Natural Breaks (Jenks) five susceptibility classes were generated (very low, low, medium, high and very high). Briefly, in the first method each class contains an equal number of features whilst in the latter the features are divided into classes whose boundaries are set where there are relatively big differences in the data values. In the current case, by using the Quantile methodology the ratio between negative and positive values of map cells' weights appeared more "equilibrate".

The differences between classes seemed emphasized locally. Using Natural Breaks (Jenks) method, a map was obtained in which cells with the value "medium susceptibility" and "high susceptibility" were predominant. As Natural Breaks (Jenks) is a data-specific classification, and suitable for representing unevenly distributed data, the related map was preferred and loaded in the Risk WebGIS of the Province of Modena Civil Protection.

\subsection{Comparison with multi-temporal orthophotos and field data}

In order to perform a direct checking of the output maps quality, they were compared with existing landslides in RER LIM (Fig. 8), orthophotos (AGEA 2008 and 2011) and field surveys (Fig. 10). 


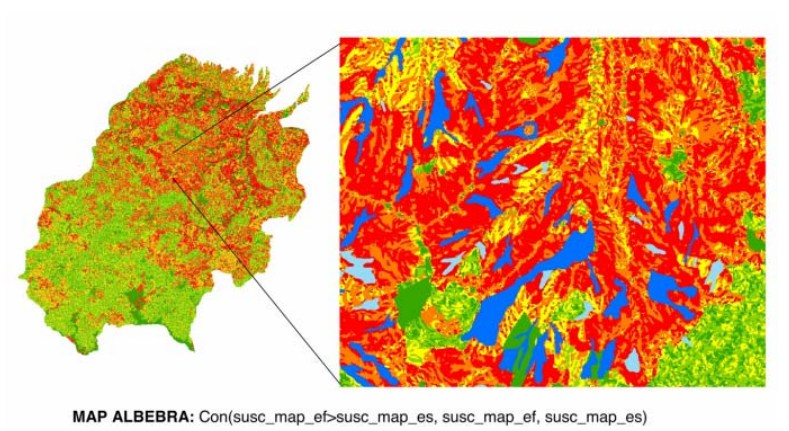

Figure 9 The combination of the two susceptibility maps (the existing landslides are in blue and cyan)

The latter were carried out in a sample area and provided good result as is shown in Fig. 10: landslide clues and warning signs (scarp retrogression, typical morphologies, sags in the road etc.) correspond to the areas of the map classified as medium to very high susceptibility. In addition, the comparison with the orthophotos provided a positive result in most cases for all the three susceptiblity maps (earth flows, slides and combined). Very frequently where landslides from RER LIM are located, the maps' cells are classified as medium to very high susceptibility, even if in some cases they are classified as low susceptibility. The reasons may be different: 1 ) the susceptibility assessment reported in the present paper did not take into account all types of landslide; 2 ) the input data might have some lack of information; 3) after the landslide occurrence it might be reached a new equilibrium. In any case, it must be remembered that the three susceptibility maps represent the "initiation points", namely points or areas where new mass movements could initiate. Therefore, while comparing susceptibility maps with the existing landslides from RER LIM, rather than considering the landslide body, it must verified what classes are assigned to the area of scarps and/or upstream of them. An interesting case is shown in Fig. 11 in which the orthophoto a) is the AGEA dated 2008 and $b$ ) is the AGEA dated 2011. The map in figures $c$ ) and d) is the combined susceptibility map of Fig. 11. The c) version is obtained with Natural Breaks (Jenks) method while the d) is made by means of Quantile method (see previous paragraph). The polygon with the blue outline is a landslide reactivation. The movement is located in the Secchia Basin near the large and well-known landslide of Boschi di Valoria (Manzi et al., 2004). It is mapped in the RER LIM and classified as active complex landslide. In the 2008 orthophoto (Fig. 11a) the landslide appears to be dormant; only the scarp is visible. On the contrary, in the 2011 orthophoto its reactivation is conspicuous. The area of the reactivation is classified as "medium", "high" and "very high" susceptibility in both maps (Fig. 11c and 11-d). In the Quantile version of the map (Fig. 11-d) there is a high compliance with the zone of the scarp. This example (not significant for the issue discussed in the previous paragraph about the symbolization methodology) highlights that the evaluation of the risk on an area like that of Fig. 11a could be reviewed by Civil Protection during planning activities by examining the susceptibility map. This is even more important considering that landslide reactivations could damage buildings and infrastructures (Galve et al., 2015; 2016) as in Fig. 5$\mathrm{b}$ where a road is intersected by the landslide accumulation.
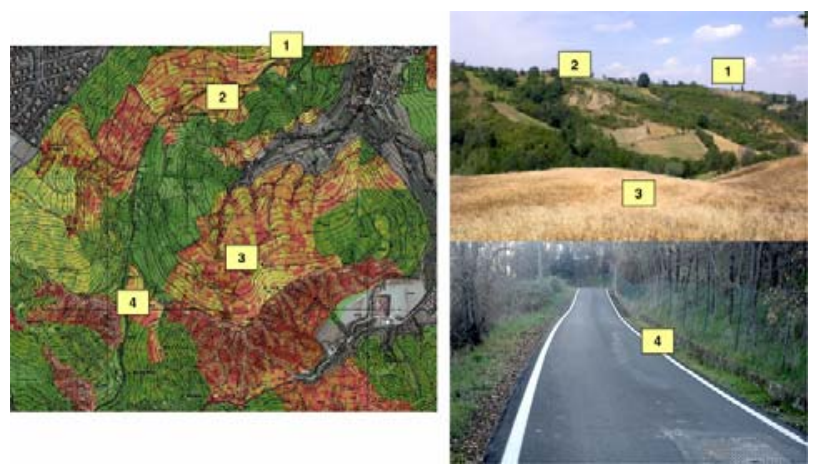

Figure 10 Direct checking of resultant susceptibility maps quality performed by means of field surveys in a sample area (Corlo Basin in the Municipality of Fiorano Modenese)

\subsection{The updating issue}

One of the main challenges in cartography is to maintain the data steadily updated. The availability of updated data is fundamental for civil protection purposes. For this reason, a simple but effective procedure was developed using Model Builder in ESRI ArcGIS 9.3.1. It is based on the following 
Assessment of landslide susceptibility for civil protection purposes by means of GIS and statistical analysis: lessons from the Province of Modena, Italy

assumption: the most part of landslide driving factors, used before for computing susceptibility maps, can be considered static except for land use which is surely subjected to a rapid evolution and therefore is dynamic. When a new land use map becomes available, it can be converted in raster and its classes uniformed with those of the 1976 land use map. After that it can be reclassified using weights calculated on 1976 land use map and added to the other weighted maps (slope, lithology and curvature) in order to obtain the new susceptibility map. Thanks to the Model Builder tool "Update SMap" (Fig. 12), even non-specialist users are able to perform these kind of operations for each landslide map (earth flows and slides), and subsequently the two updated maps could be combined into one using the conditional equation (3) in ESRI Spatial Analyst Map Algebra.

\subsection{Discussion}

The susceptibility analysis led to a better understanding of the most important factors for slope instability in the study area. It made available new susceptibility maps useful for civil protection purposes in Province of Modena that can be loaded as thematic layers in the Risk WebGIS, including the input factor maps (e.g. lithology, slope, aspect, curvature, slope position index and distance from roads). The final susceptibility map documents are good decision support tools suitable for the elaboration of events' scenarios in the framework of civil protection forecast and prevention programmes (Soldati et al., 2014). When overlaid with elements at risk (such as buildings, roads and other infrastructures, population etc.), that is easy to be performed with the Risk WebGIS, Civil Protection can obtain damage scenarios useful for the provincial emergency plan on hydrogeological risk. The 1:10,000 map scale, consistent with those of the input data, makes them usable for wide area (supramunicipal) forecast and prevention purposes like provincial territory is. Other than the resultant susceptibility maps, the analysis itself highlighted weak points and gaps of the existing inventory map that could be partly fixed by Civil Protection. In fact, the Modena Civil Protection collects data on landslide from municipalities, by means of the SRD (data collecting system), the module connected with the Risk WebGIS, and stores them in the geodatabase. Highlighted gaps could drive a revision of the data collection forms. About the updating issue, the tool implemented for updating susceptibility maps could be used also for a small part of the territory, when new data on land use are available partially, or to design landslide susceptibility scenarios assuming a variation of land use.

\section{Conclusions}

The present paper deals with the issue of risk forecasting in civil protection, which consists of activities aimed to study and detect what are the causes of hazardous events, namely landslides, as well as to identify areas particularly prone to mass movements for zoning them and plan measures to mitigate related risk. In the case of the Province of Modena, earth flows and slides happen frequently and are widespread, hence they generate critical situations for the population, damaging infrastructure, especially roads, and sometimes buildings. They often require the intervention of Civil Protection even when they are not extensive. Thus, a susceptibility assessment for these two types of landslides was performed and described in the present paper. Considering the above mentioned limitations due to input data, the resulting models predict an acceptable number of landslides. In both cases, earth flows and slides, the final susceptibility map is the sum of the following weighted factor maps: lithology, slope, land use and curvature. They resulted to be the most important factors which drive landslide phenomena in the study area. In order to take into account current situation, weights calculated by means of the 1976 land use map 


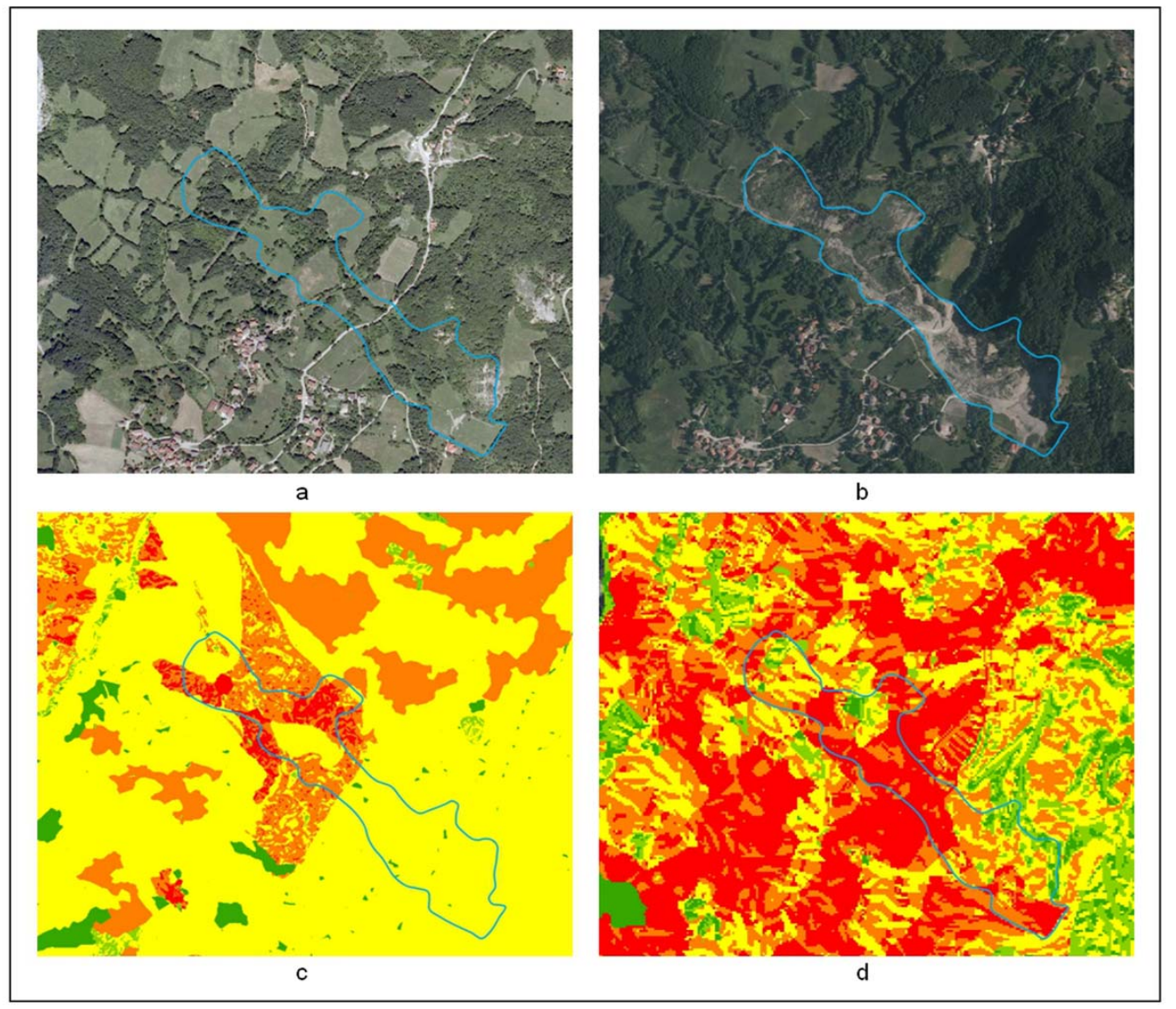

Figure 11 Orthophoto a) is AGEA 2008 and b) is AGEA 2011. The depicted map is the combination susceptibility map of Figure 9. The c) version is obtained with Natural Breaks (Jenks) simbology classification method whilst d) is made by means of Quantile method. The polygon with blue outline is a landslide reactivation, existing in RER LIM, the shape of which is clearly recognizable in 2011.

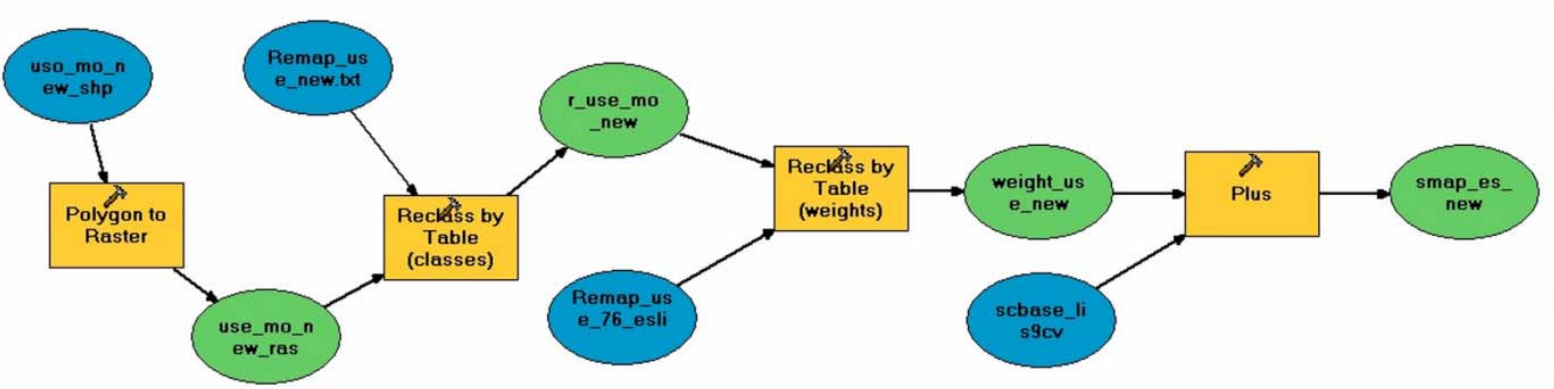

Figure 12 The Model Builder scheme of ESRI ArcGIS reporting operations needed to update the susceptibility maps. The tool designed for updating slide susceptibility map is shown in the figure; the one for earth flow map is similar. 
Assessment of landslide susceptibility for civil protection purposes by means of GIS and statistical analysis: lessons from the Province of Modena, Italy

(assumed to be the situation before the existing landslides occurred) were assigned to those of 2008. Therefore, two susceptibility maps were computed for as many types of landslides. These documents are useful for skilled users but difficult to be interpreted by non-specialists, such as Civil Protection users who were supplied with a third document resulted from the combination of the two maps. In order to increase the intelligibility of the map even more, two classification methods of ESRI ArcGIS were tested to symbolize the map: Quantile and Natural Breaks (Jenks). The range of weight values were grouped into only five legend classes. In fact, an excessive number of classes could confuse the user and lead to a wrong interpretation of the map information content. Both tests on the two classification methods led to good results, but the Natural Breaks (Jenks) method was preferred to continue the test that is still to be concluded. In fact, at this point the map was considered ready to be loaded in the Risk WebGIS of the Modena Province Civil Protection. The example of Fig. 11 demonstrates how the susceptibility maps can be useful for Civil Protection in order to include in their plans some landslide apparently dormant in certain period of time.

Another issue to be faced was the "updating question", well known in cartography. Maps risk to age before users become familiar with them. Hence, some custom tools were developed for ESRI ArcGIS with Model Builder assuming that only land use is a dynamic factor. The procedure is simple enough to allow even users with little experience of GIS to update maps. Having worked on a wide study area (about $\left.1300 \mathrm{~km}^{2}\right)$, using a quite detailed DTM $(5 \times 5)$, and a statistical method easy to apply (Weight of Evidence) which has also allowed the development of an automated GIS procedure for updating the landslide susceptibility maps, makes what is illustrated in this paper an example for other Civil Protection organizations, other than Province of Modena one. In fact, if on the one hand Civil Protection needs detailed data, on the other hand at a supra-municipal level an overview of hazardous phenomena is required to perform planning activities. In addition, the actions undertaken to make the susceptibility maps more intelligible, issue seldom investigated by those who assess landslide susceptibility, become fundamental in a context of civil protection.

In conclusion, the experience conducted in the framework of the research discussed in this paper is exportable to other civil protection contexts where the integrated planning among stakeholders (i.e. regions, provinces, municipalities etc.), the constant and dynamic updating of geographic information, as well as an efficient system to share them (namely WebGIS applications), is considered strategic for risk forecasting and preventing, and emergency management.

\section{Acknowledgements}

The work illustrated in the present paper was led in the framework of an agreement between the University of Modena and Reggio Emilia (UNIMORE) and the Province of Modena Civil Protection (MPCP) on GIS applied to risk forecasting and prevention (Scientific responsible: M. Soldati). The paper is also part of the PRIN 2010-11 MIUR Project on the "Dynamics of morphoclimatic systems as a response of global changes and induced geomorphological risks" (Co-ordinator: C. Baroni; Research Unit Responsible: M. Soldati). The authors are grateful to Dr. Rita Nicolini (MPCP) and to Prof. Doriano Castaldini (UNIMORE) for support and source materials, as well as to Mrs. Megan Sumner van Gils. Regarding the methodological aspects, this research was possible thanks to the collaboration with the ITC of Enschede, The Netherlands.

\section{References}

Bertolini G, Corsini A, Tellini C. 2017. Fingerprints of Large-Scale Landslides in the Landscape of the Emilia Apennines. In: Landscapes and Landforms of Italy, Soldati M., Marchetti M. (eds.). Springer Publishing International Publishing AG, Cham: 215224.

Bonham-Carter GF. 1994. Geographic Information Systems for Geoscientists; modeling with GIS. Computer Method in the Geoscience 13. Pergamon Press: Ontario.

Bohnam-Carter GF, Agterberg FP, Wright DF. 1989. Weights of evidence modelling: a new approach to 
mapping mineral potential. In: Statistical application in Earth Sciences, Agterberg F.P., Bohnam-Carter G.F. (eds.). Geological Survey of Canada, Paper 89-9: 171-183.

Borgatti L, Soldati M. 2010. Landslides and climatic change. In: Geomorphological Hazards and Disaster Prevention, Alcántara-Ayala I., Goudie A.S. (eds.). Cambridge University Press, Cambridge; 87-95.

Buja K. 2009. Find Ajacent Features extension for ArcGIS 9.3.

http://arcscripts.esri.com/details.asp?dbid=15805. Accessed 31 March 2015

Carrara A, Cardinali M, Guzzetti F, Reichenbach P. 1995. GIS technology in mapping landslide hazard. In: Geographical Information Systems in Assessing Natural Hazards, Carrara A, Guzzetti F (eds.). Kluwer Academic Publisher: Dordrecht, The Netherlands; 135-175.

Castaldini D, Ghinoi A. 2007. Geomorphological Hazards Affecting Main Productive Areas in the Mountain Basin of the Panaro River (Modena Apennines, Italy): a Case Study. Analele Universitatii din Oradea, Seria Geografie, tom. XVII, Editura Universitatii din Oradea 2007: 11-20.

Castaldini D. with contributions by Valdati J, Ilies DC, Molinari E. 2003. Guide to the Excursion in the Modena Apennines. In: Workshop on Geomorphological sensitivity and system response, Castaldini D, Gentili B, Materazzi M, Pambianchi G (eds.). Arte Lito: Camerino (MC); 143-167.

Chalkias C, Kalogirou S, Ferentinou M. 2014. Landslide susceptibility map of the Peloponnese peninsula in South Greece. Journal of Maps 10(2): 211-222.

Chung CF, Fabbri AG. 2008. Predicting landslides for risk analysis - Spatial models tested by a crossvalidation technique. Geomorphology 94: 438-452.

Chung CF, Fabbri AG. 2003. Validation of Spatial Prediction Models for Landslide Hazard Mapping. Natural Hazards 30: 451-472.

Chung CF, Fabbri AG. 1999. Probabilistic Prediction Models for Landslide Hazard Mapping. Photogrammetric Engineering and Remote Sensing 65: 1389-1399.

Cruden DM, Varnes DJ. 1996. Landslides types and processes. In: Landslides: Investigation and Mitigation. Transportation Research Board Special Report, Turner AK, Schuster RL (eds.), 247. National Academy Press: WA. 36-75.

Dilts T. 2010. Topography Tools for ArcGIS 9.3, toolbox based on Jenness (2006) Arcview 3.x extention. http://arcscripts.esri.com/details.asp?dbid=15996.

Accessed 31 March 2015
Fell R, Corominas J, Bonnard C, Cascini L, Leroi E, Savage WZ. 2008. Guidelines for landslide susceptibility, hazard and risk zoning for land-use planning. Engineering Geology 102(3-4): 99-111.

Galli M, Ardizzone F, Cardinali M, Guzzetti F, Reichenbach P. 2008. Comparing landslide inventory maps. Geomorphology 94: 268-289.

Galve JP, Cevasco A, Brandolini P, Piacentini D, Azañón JM, Notti D, Soldati M, 2016. Cost-based analysis of mitigation measures for shallow-landslide risk reduction strategies. Engineering Geology 213: 142157.

Galve JP, Cevasco A, Brandolini P, Soldati M. 2015. Assessment of shallow landslide risk mitigation measures based on land use planning through probabilistic modeling. Landslides 12(1): 101-114.

Generali M, Pizziolo M. 2013. The Susceptibility Map for Shallow Landslides Initiation in the Emilia Romagna Region (Italy). In: Landslide Science and Practice, Vol. 1, Margottini C, Canuti P, Sassa K. (eds.). SpringerVerlag Berlin Heidelberg: 435-450.

Gonzalez J. 2009. Remove Small Polygons extension for ArcGIS 9.3.

http://arcscripts.esri.com/details.asp?dbid=16541. Accessed 31 March 2015

Guzzetti F, Mondini AC, Cardinali M, Fiorucci F, Santangelo M, Chang KT. 2012. Landslide inventory maps: new tools for an old problem. Earth-Science Reviews 112: 42-66.

Guzzetti F, Reichenbach P, Ardizzone F, Cardinali M, Galli M. 2006. Estimating the quality of landslide susceptibility models. Geomorphology 81: 166-184.

Guzzetti F, Carrara A, Cardinali M, Reichenbach P. 1999. Landslide hazard evaluation: an aid to a sustainable development. Geomorphology 31: 181-216.

Hussin HY, Zumpano V, Reichenbach P, Sterlacchini S, Micu M, van Westen C, Balteanu D. 2016. Different landslide sampling strategies in a grid-based bivariate statistical susceptibility model. Geomorphology 253: 508-523.

International Association of Engineering Geology (IAEG). 1976. Engineering Geology Maps: A guide to Their Preparation. UNESCO Press: Paris.

Jenness J. 2006. Slope Position Index, extension for ArcView 3.x, Jenness Enterprises. http://www.jennessent.com/arcview/tpi.htm. Accessed 12 October 2015.

Province of Modena. 2012. Popolazione residente in provincia di Modena al $1^{\circ}$ gennaio 2012. Note Congiunturali. http://www.provincia.modena.it/allegato.asp?ID =177 076. Accessed 12 October 2017. 
Assessment of landslide susceptibility for civil protection purposes by means of GIS and statistical analysis: lessons from the Province of Modena, Italy

Province of Modena. 2009. Piano Territoriale di Coordinamento Provinciale (PTCP). http://www.territorio.provincia.modena.it/page.asp?I DCategoria $=121 \&$ IDSezione $=3930$. Accessed 12 October 2017.

Manzi V, Leuratti E, Lucente CC, Medda E, Guerra M, Corsini A. 2004. Historical and recent hydrogeological instability in the Monte Modino area: Valoria, Tolara and Lezza Nuova landslide reactivations (Dolo - Dragone valleys, Modena Apennines, Italy). Geoacta 3: 1-13.

Nicolini R, Gelmuzzi F, Virga M, Liberatoscioli E, Galantini G. 2012. Le tecnologie WebGIS in Provincia di Modena. In: La Protezione Civile Italiana 1/2012: $120-127$.

Parsons A. 1988. Hillslope form. Routledge, 212.

Petschko H, Brenning A, Bell R, Goetz J, Glade T, 2014. Assessing the quality of landslide susceptibility maps - case study Lower Austria. Natural Hazards and Earth System Sciences 14: 95-118.

Piacentini D, Devoto S, Mantovani M, Pasuto A, Prampolini M, Soldati M. 2015. Landslide susceptibility modeling assisted by Persistent Scatterers Interferometry (PSI): an example from the northwestern coast of Malta. Natural Hazards 78: 681-697

Piacentini D, Troiani F, Soldati M, Notarnicola C, Savelli D, Schneiderbauer S, Strada C. 2012. Statistical analysis for assessing shallow-landslide susceptibility in South Tyrol (south-eastern Alps, Italy). Geomorphology 151-152: 196-206.

Poli S, Sterlacchini S. 2007. Landslide Representation Strategies in Susceptibility Studies using Weights-ofEvidence Modeling Technique. Natural Resources Research 16(2): 121-134.

Siddiqui S, Soldati M. 2014. Appraisal of active tectonics using DEM-based hypsometric integral and trend surface analysis in Emilia-Romagna Apennines, northern Italy. Turkish Journal of Earth Sciences 23: 277-292.

Soeters R, van Westen CJ. 1996. Slope instability recognition, analysis, and zonation. In: Landslides, investigation and mitigation, Turner A.K., Schuster R.L. (eds.). Transportation Research Board, National Academy Press, National Research Council, Special Report 247: Washington D.C.; 129-177.

Soldati M, Ghinoi A, Pattuzzi E. 2014. Il ruolo della geomorfologia negli studi di rischio e resilienza da frana nel contesto dei cambiamenti climatici. Atti Società Naturalisti e Matematici di Modena 145: 43-63.

Soldati M, Borgatti L. 2009. Paleoclimatic significance of Holocene slope instability in the Dolomites (Italy). Geografia Fisica e Dinamica Quaternaria 32(1): 83-88.

Sterlacchini S, Ballabio C, Blahut J, Masetti M, Sorichetta A. 2011. Spatial agreement of predicted patterns in landslide susceptibility maps. Geomorphology 125: 51-61.

Van Den Eeckhaut M, Hervás J. 2012. State of the art of national landslide databases in Europe and their potential for assessing landslide susceptibility, hazard and risk. Geomorphology 139-140: 545-558.

Van Westen CJ, Asch TWJ, Soeters R. 2005. Landslide hazard and risk zonation - why is it still so difficult? Bulletin of Engineering Geology and the Environment 65: 167-184.

Van Westen CJ, Rengers N, Soeters R. 2003. Use of Geomorphological Information in Indirect Landslide Susceptibility Assessment. Natural Hazards 30: 399-419.

Zêzere JL. 2002. Landslide susceptibility assessment considering landslide typology. A case study in the area north of Lisbon (Portugal). Natural Hazards and Earth System Sciences 2: 73-82. 